\title{
Multiplicação microbiana no leite cru armazenado em tanques de expansão direta
}

\author{
Microbial multiplication in raw milk stored in direct expansion bulk tanks
}

\author{
Natalia Luiza Machado Reche $^{\mathrm{I}}$ André Thaler Neto ${ }^{\mathrm{I}}$ Loredana D'Ovideo $^{\mathrm{I}}$ Nadine Cristina Felipus ${ }^{\mathrm{I}}$ \\ Luana Cristina Pereira ${ }^{\mathrm{I}}$ Leonardo Leite Cardozo ${ }^{\mathrm{I}}$ Robson Guilherme Lorenzetti ${ }^{\mathrm{I}}$ \\ Lídia Cristina Almeida Picinin ${ }^{I}$
}

\section{RESUMO}

O presente estudo objetivou avaliar o efeito do tempo de armazenagem do leite em tanques de expansão direta, modelo de duas e quatro ordenhas, sobre a contagem bacteriana total (CBT) e a contagem de bactérias psicrotróficas (CBP). As avaliações foram conduzidas em 19 propriedades leiteiras, localizadas nas regiões Serrana e Oeste de Santa Catarina, as quais utilizavam equipamentos de refrigeração do leite por expansão direta, modelo de duas ou quatro ordenhas, com taxa de ocupação variando de 60 a 100\% de sua capacidade. Antes e após cada ordenha, foram coletadas amostras de leite para análise de CBT, CBP e contagem de células somáticas (CCS), totalizando aproximadamente 36 horas de armazenagem (quatro ordenhas). $O$ tempo de armazenagem do leite cru resfriado não afetou a $C B T$ e CBP $(P>0,05)$ em ambos os modelos. $O$ modelo de tanque de expansão afetou somente a $C B P(P<0,05)$, com média inferior para amostras de leite de tanques de duas ordenhas em relação

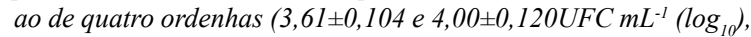
respectivamente). Conclui-se que tanques de resfriamento por expansão direta, utilizados dentro de suas especificações quanto ao volume de leite a ser resfriado, permitem a manutenção da $C B T$ e da CBP em sistemas de transporte do leite ao laticínio a cada 48 horas.

Palavras-chave: tempo, temperatura contagem bacteriana total, contagem de bactérias psicrotróficas.

\section{ABSTRACT}

The purpose of this study was to evaluate the effect of the cold storage period of raw milk in bulk tanks, using two and four milking models, on total bacterial count (TBC) and psychrotrophic bacterial count (PBC). A total of 19 dairy farms, located in West and Uplands of the Santa Catarina State - Brazil, was been evaluated. Each dairy farm had direct expansion bulk milk tank and an occupancy rate varying from $60 \%$ to $100 \%$. Samples were collected before and after each milking procedure to determine $P B C$ and $T B C$, totalizing four milking and a storage period of 36 hours. The storage time did not affect TBC and $P B C$ $(P>0.05)$. The bulk tank model only affected the $P B C(P<0.05)$, with two-milking model presenting a lower mean than fourmilking model $\left(3.61 \pm 0.104\right.$ and $\left.4.00 \pm 0.120 C F U L^{-1}\left(\log _{10}\right)\right)$. It was possible to conclude that bulk tanks, when used properly concerning raw milk volume to be chilled, allow the TBC and PBC to remain stable in the transportation systems of raw milk to the industry each 48 hours.

Key words: time. Temperature, total bacterial count, psychrotrophic bacteria count, hygiene.

\section{INTRODUÇÃO}

A Instrução Normativa № 62 (IN 62) estabeleceu o limite máximo de 100.000 unidades formadoras de colônia (UFC) $\mathrm{mL}^{-1}$ para contagem bacteriana total (CBT) nas regiões (região Sul, Sudeste e Centro-Oeste, a partir de 2016, mantendo-se o tempo de armazenagem do leite nas propriedades rurais por até 48 horas (BRASIL, 2011). Fatores como o tempo de armazenamento na propriedade leiteira, associado às oscilações na temperatura, causadas pela adição de um novo volume de leite a cada ordenha, utilização inadequada dos tanques de resfriamento e baixas condições de higiene durante a obtenção do leite podem contribuir para o aumento da contagem bacteriana do leite cru, armazenado em tanques resfriadores por expansão direta (LORENZETTI, 2006; VALLIN et al., 2009).

'Universidade do Estado de Santa Catarina (UDESC), Av. Luiz de Camões, CP 2090, Conta Dinheiro, 88520-000, Lages, SC, Brasil. E-mail: natty_vet@yahoo.com.br. *Autor para correspondência. 
A implementação do resfriamento do leite nas propriedades leiteiras minimiza a proliferação de micro-organismos mesófilos, porém, favorece o desenvolvimento de micro-organismos psicrotróficos (CEMPÍRKOVÁ \& MIKULOVÁ, 2009). Essas bactérias com capacidade psicrotrófica produzem enzimas extracelulares lipolíticas e proteolíticas, que permanecem ativas após o tratamento térmico e, consequentemente, geram alterações sensoriais, redução do tempo de vida de prateleira e do rendimento industrial dos produtos lácteos (CHAMPAGNE et al., 1994; ARCURI et al., 2008).

Um dos fatores mais importantes para qualidade final dos produtos lácteos é a contaminação inicial do leite cru, visto que alguns micro-organismos podem dobrar sua população a cada 20 ou 30 minutos (GUERREIRO et al., 2005). A contaminação inicial do leite pode ser consequência de deficiências no manejo e higiene da ordenha, manutenção e desinfecção inadequadas dos equipamentos, refrigeração ineficiente e mão-de-obra desqualificada (VALLIN et al., 2009).

No mercado brasileiro, há dois modelos de resfriadores denominados de tanques de duas e de quatro ordenhas, os quais possuem, respectivamente, capacidade para resfriar 50 e $25 \%$ de seu volume à temperatura de $4^{\circ} \mathrm{C}$, em um período de até três horas após a ordenha (CBQL, 2006). Sabe-se que a diferença entre os modelos de resfriadores afeta tanto o custo do equipamento, como o consumo de energia, consumo de material de limpeza, valor da reposição do compressor e custo de manutenção (VINHOLIS \& BRANDÃO, 2009). Entretanto, ainda são escassas as informações disponíveis sobre a capacidade de manutenção da qualidade microbiológica do leite ao longo do tempo de armazenamento, considerando a peculiaridade de que a massa de leite resfriado recebe um volume de leite com temperatura elevada a cada ordenha, gerando oscilação de temperatura do leite ao longo do período de armazenamento.

Informações sobre possíveis diferenças entre os modelos de resfriadores, quanto à eficiência de resfriamento e controle microbiológico do leite, são necessárias, devido à possibilidade de menor capacidade de manutenção da qualidade microbiológica do leite em resfriadores por expansão direta, modelo de quatro ordenhas, como consequência da sua menor capacidade de resfriamento a cada ordenha.

Em função disso, o presente estudo objetivou avaliar o efeito do tempo de armazenagem do leite sobre a contagem bacteriana total (CBT) e contagem de bactérias psicrotróficas (CBP) em tanques de expansão, modelos de duas ordenhas e quatro ordenhas.

\section{MATERIAL E MÉTODOS}

\section{Amostragem}

O estudo foi conduzido em 19 propriedades leiteiras, localizadas em duas regiões de Santa Catarina (Serrana e Meio-Oeste), as quais possuíam equipamentos de refrigeração do leite através de expansão direta, modelo de duas ou quatro ordenhas, com ocupação entre 60 e $100 \%$ da sua capacidade, no intervalo entre dois transportes de leite. Em todas as propriedades, o leite era transportado a granel para a indústria a cada 48 horas.

O procedimento experimental foi realizado com duas repetições em cada propriedade, com intervalo mínimo de duas semanas. Para obtenção de informações referentes às boas práticas de higiene e manejo de ordenha foi aplicado questionário estruturado aos responsáveis pela ordenha, envolvendo a infraestrutura da propriedade para a ordenha, os procedimentos de preparo do animal para ordenha, fonte de água, procedimentos de higiene e manutenção dos equipamentos de ordenha e refrigeração.

As amostras de leite para análise de CBT, CCS e CBP foram coletadas em alíquotas de $50 \mathrm{~mL}$, em frascos estéreis, contendo o conservante Azidiol ${ }^{\circledR}$, Bronopol $^{\circledR}$ e sem conservante, respectivamente. Essas amostras foram coletadas após a $1^{\mathrm{a}}$ ordenha e consecutivamente antes e após a 2 $2^{\mathrm{a}}, 3^{\mathrm{a}}$ e $4^{\mathrm{a}}$ ordenha, totalizando sete amostras por ciclo (aproximadamente 36 horas de armazenagem) e 266 amostras no experimento. As amostras foram acondicionadas em caixas isotérmicas, contendo gelo reciclável e encaminhadas ao laboratório, sendo que as amostras de CBP foram processadas no tempo máximo de duas horas após o término da ordenha e as amostras para CBT e CCS, processadas em até quatro dias, conforme o método de análise do laboratorial da Universidade do Contestado (UnC/CIDASC) em Concórdia - SC. Durante todo período de armazenagem, a temperatura do leite no tanque de expansão direta foi registrada por meio de datalogger da marca Akson ${ }^{\circledR}$ (modeloAK285), em intervalos de cinco minutos.

\section{Análises}

No laboratório, as amostras para CBP foram imediatamente inoculadas, em triplicata, por meio do método de espalhamento em superfície no ágar padrão para contagem - Plate Count Agar (PCA), com incubação a $7^{\circ} \mathrm{C}\left( \pm 1^{\circ} \mathrm{C}\right)$, por 10 dias

Ciência Rural, v.45, n.5, mai, 2015. 
(SILVA et al., 2010). Após este período, as colônias formadas foram enumeradas (no intervalo entre 25 a 250UFC por placa) e o valor obtido foi multiplicado pela recíproca da diluição correspondente e do volume da alíquota utilizado na inoculação $(0,1 \mathrm{ml})$, sendo os resultados expressos em UFC $\mathrm{mL}^{-1}$.

As amostras para CBT e CCS foram quantificadas pelo método de citometria de fluxo, utilizando um equipamento Bentley Bactocount ${ }^{\circledR}$ IBC no laboratório da UNC/CIDASC em Concórdia - SC.

$\mathrm{O}$ delineamento experimental foi inteiramente casualizado, em arranjo fatorial $2 \times 2 \times 3 \times 2$, sendo os fatores as duas regiões em que o estudo foi desenvolvido (Serrana ou Meio-Oeste de Santa Catarina), os dois modelos de resfriadores de expansão direta (duas e quatro ordenhas), os três tempos de armazenamento do leite nos resfriadores (12, 24 e 36 horas) e os dois momentos de amostragem do leite (antes e após a ordenha). Foram analisadas as variáveis independentes contagem bacteriana total (CBT) e contagem de bactérias psicrotróficas (CBP), sendo realizada transformação logarítmica $\left(\log _{10}\right)$, visando normalidade dos resíduos, a qual foi testada pelo teste de Shapiro Wilks. Os dados foram submetidos à análise de variância, com medidas repetidas no tempo dentro de cada propriedade leiteira, utilizando-se o procedimento MIXED do pacote estatístico SAS (SAS, 2005), sendo as médias comparadas pelo teste de Tukey. Foram avaliados os dados a partir de aproximadamente 12 horas de armazenamento (antes da segunda ordenha). O modelo estatístico foi composto pelas variáveis explanatórias: região em que se localizava a propriedade, modelo de tanque de expansão, tempo de armazenamento do leite, momento de amostragem do leite, as interações entre estas variáveis, além das covariáveis percentagem de ocupação do tanque de expansão e contaminação inicial do leite (CBT ou CBP antes do resfriamento, imediatamente após a primeira ordenha).

A relação entre algumas técnicas de manejo de ordenha e indicadores, relacionada à infraestrutura para ordenha com a contaminação inicial do leite, foi avaliada através de análise multivariada. Empregouse a técnica de correspondência múltipla, utilizandose o procedimento CORRESP do pacote estatístico SAS (SAS, 2005).

\section{RESULTADOS E DISCUSSÃO}

A partir da análise dos dados obtidos por meio do questionário aplicado nas 19 propriedades rurais, obteve-se produção média de leite de
$389,6 \mathrm{~L} \mathrm{dia}{ }^{-1}$, variando entre 200 a $650 \mathrm{~L} \mathrm{dia}{ }^{-1}$. O leite armazenado na propriedade correspondeu a 4 ordenhas, apresentando taxa de ocupação entre 60 a $100 \%$, com média de 73,42 e $78,6 \%$ para tanques de duas e quatro ordenhas, respectivamente. Todas as propriedades realizavam ordenha mecânica, sendo que $42,1 \%$ das propriedades possuíam sistema de ordenha balde ao pé e $57,9 \%$ ordenha canalizada.

A contagem inicial de micro-organismos no leite apresentou média de 91.666UFC $\mathrm{mL}^{-1} \mathrm{e}$ 36.459 UFC $\mathrm{mL}^{-1}$ para contagem bacteriana total (CBT) e contagem de bactérias psicrotróficas (CBP), respectivamente. A contagem inicial de micro-organismos está relacionada à aplicação de boas práticas de manejo, visto que, dos produtores avaliados, 94,7\% dispunham de água aquecida na sala de ordenha, 22,2\% realizavam controle de temperatura da água e 78,9\% aplicavam detergentes adequados (alcalino-clorado e ácido) para higiene de equipamentos de ordenha e refrigeração. Os valores médios de CBT estão em acordo com os valores máximos exigidos pela IN 62, previstos para vigorar a partir de 2016 (100.000UFC $\left.\mathrm{mL}^{-1}\right)$. Não há limite regulatório vigente para $\mathrm{CBP}$, contudo a literatura relata que, quando a manipulação do leite ocorre sob condições higiênico-sanitárias adequadas, a presença de micro-organismos psicrotróficos se limita a $10 \%$ da microbiota total do leite fresco, enquanto que, em situações problemáticas, pode representar 75\% (NIELSEN, 2002). No presente estudo, a proporção inicial de micro-organismos psicrotróficos foi de $34,69 \%$ da microbiota total. As condições do presente estudo divergem das observadas em alguns estudos realizados com leite estocado em temperatura constante no Brasil (ARCURI et al., 2004; LORENZETTI, 2006), nos quais a CBT estava acima do limite estabelecido pela IN 62 (BRASIL, 2011).

O tempo de armazenagem não afetou CBT e CBP $(\mathrm{P}>0,05)$ (Tabela 1$)$, evidenciando que o leite pode ser transportado em intervalos de 48 horas para a indústria, sendo possível manter a qualidade microbiológica do leite em tanques resfriadores por expansão direta, nos modelos de duas ou quatro ordenhas, dentro deste período. A contaminação inicial do leite (após a primeira ordenha, sem resfriamento) afetou a CBT e a $\mathrm{CBP}(\mathrm{P}<0,0001)$. No entanto, a taxa de ocupação dos tanques de expansão não afetou CBT e CBP, assim como não foi observada interação entre os fatores analisados $(\mathrm{P}>0,05)$.

Os resultados corroboram a avaliação da armazenagem de leite cru resfriado por $0,24,48 \mathrm{e}$ 72 horas, realizada em propriedades do Estado de 
Tabela 1 - Médias dos quadrados mínimos \pm erros-padrão da contagem bacteriana total (CBT) e contagem de bactérias psicrotróficas (CBP) de acordo com o tempo aproximado de armazenamento, do modelo de resfriador, do momento da coleta da amostra de leite em relação à ordenha e da região.

\begin{tabular}{|c|c|c|c|}
\hline Variável & Classe & $\mathrm{CBT}\left(\log _{10} \mathrm{UFC} \mathrm{mL}^{-1}\right)$ & $\mathrm{CBP}\left(\log _{10} \mathrm{UFC} \mathrm{mL}^{-1}\right)$ \\
\hline \multirow{3}{*}{ Tempo de armazenamento } & 12 horas & $4,58 \pm 0,036$ a & $3,78 \pm 0,081 \mathrm{a}$ \\
\hline & 24 horas & $4,57 \pm 0,036 \mathrm{a}$ & $3,81 \pm 0,081 \mathrm{a}$ \\
\hline & 36 horas & $4,54 \pm 0,036 \mathrm{a}$ & $3,82 \pm 0,081 \mathrm{a}$ \\
\hline \multirow{2}{*}{ Resfriador } & 2 ordenhas & $4,51 \pm 0,046 \mathrm{a}$ & $3,61 \pm 0,104 \mathrm{~b}$ \\
\hline & 4 ordenhas & $4,61 \pm 0,052 \mathrm{a}$ & $4,00 \pm 0,120 \mathrm{a}$ \\
\hline \multirow{2}{*}{ Amostragem do leite } & Antes da ordenha & $4,60 \pm 0,041 \mathrm{a}$ & $3,83 \pm 0,079 \mathrm{a}$ \\
\hline & depois da ordenha & $4,55 \pm 0,041 \mathrm{a}$ & $3,78 \pm 0,079 \mathrm{a}$ \\
\hline \multirow{2}{*}{ Região } & Serrana & $4,51 \pm 0,045 \mathrm{a}$ & $3,65 \pm 0,102 \mathrm{a}$ \\
\hline & Oeste & $4,61 \pm 0,052 \mathrm{a}$ & $3,96 \pm 0,117 \mathrm{a}$ \\
\hline
\end{tabular}

Médias seguidas de letras diferentes para uma mesma variável diferem pelo teste de Tukey $(\mathrm{P}<0,05)$.

Goiás, na qual o tempo de armazenagem não afetou a CBP (SANTOS, 2008). Da mesma forma, os resultados de um estudo de modelagem matemática para a multiplicação bacteriana no leite cru, o qual também evidenciou que o tempo de refrigeração não influenciou no desenvolvimento bacteriano (FRÜHLING, 2013).

Porém, os resultados obtidos divergem de um estudo realizado em 30 propriedades leiteiras no Paraná, no qual o leite cru estocado por 24 e 48 horas apresentou aumento da microbiota $(\mathrm{P}<0,05)$ em relação ao estocado por duas horas. Da mesma forma, a avaliação do leite com 24 e 48 horas de armazenagem em ambiente controlado, a partir de amostras de leite individual de vaca, tanque de expansão e silo industrial, apresentaram aumento progressivo de micro-organismos psicrotróficos nas 48 horas de armazenagem (LEITNER et al., 2008).

Experimentos conduzidos em laboratório têm demonstrado que amostras de leite armazenados em ambiente controlado apresentam taxa de multiplicação microbiana linear (ARCURI et al., 2004; LORENZETTI, 2006). Em condições a campo, a entrada de leite quente a cada ordenha é uma variável fundamental, pois gera oscilação na temperatura do leite, resultando em alteração da microbiota bacteriana presente e efeito de diluição, devido à entrada de um novo volume de matéria-prima. Além disso, a taxa de multiplicação dos micro-organismos está relacionada à contaminação inicial do leite.

O tempo de resfriamento na propriedade demonstrou ser um fator coadjuvante na qualidade do leite cru, ressaltando a importância das boas práticas de manejo na ordenha, visto que a contagem inicial de micro-organismos se manteve estável ao longo da armazenagem do leite cru. O sucesso na aplicação das boas práticas possibilita a redução em média de $87 \%$ da CBT, independente do sistema de ordenha adotado pela propriedade (VALLIN et al., 2009).

O modelo de tanque resfriador não afetou a CBT $(\mathrm{P}<0,05)$, uma vez que ambos os modelos ( 2 ou 4 ordenhas) atingiram temperaturas baixas suficientes para inibir a proliferação de micro-organismos mesófilos. Deve-se considerar que a média da CBT foi muito abaixo da contaminação inicial de outros trabalhos com leite cru resfriado no Brasil, nos quais as médias superavam o limite vigente estabelecido pela IN 62 (SANTOS et al., 2008; CITADIN et al., 2009; VALLIN et al., 2009; CATANIO et al., 2012). Além disso, no presente estudo, foram conduzidas análises em propriedades, nas quais a capacidade nominal dos resfriadores não foi excedida no período entre os transportes de leite.

A CBP foi afetada pelo modelo de tanque de expansão $(\mathrm{P}<0,05)$ (Tabela 1$)$. Na figura 1 , são apresentadas as temperaturas médias nos períodos iniciais e finais de cada ordenha e intervalo entre ordenhas. Verifica-se que entre a $1^{\underline{a}}$ ordenha e o $1^{o}$ intervalo, em média, os tanques de expansão direta, modelo de duas ordenhas, apresentaram redução de temperatura mais pronunciada do que os tanques de quatro ordenhas. Essa diferença na oscilação da temperatura do leite, nas primeiras horas de armazenagem, pode ser o fator determinante para uma maior proliferação de micro-organismos psicrotróficos em tanques de quatro ordenhas, uma 




vez que algumas espécies desses micro-organismos apresentam tempo de geração de 20 a 30 minutos quando em temperatura de $7^{\circ} \mathrm{C}$ (GUERREIRO et al., 2005).

O momento de coleta das amostras de leite (antes $x$ depois da ordenha) não afetou a CBT e a CBP $(\mathrm{P}>0,05)$ (Tabela 1), havendo uma possível desestabilização da curva de crescimento de micro-organismos, em consequência da oscilação de temperatura do leite. Tampouco foi observada diferença entre as regiões de Santa Catarina, avaliadas quanto a CBT e CBP.

A relação entre a adoção de algumas práticas de manejo de ordenha e da infraestrutura de ordenha, com a contaminação inicial, estão apresentados na figura 2. As duas dimensões formadas na análise de correspondência múltipla explicaram $71,51 \%$ da variação total. A CBP e a CBT inicial do leite apresentaram relação próxima entre si, tanto altas como baixas contaminações. CEMPÍRKOVÁ \& MIKULOVÁ (2009), avaliando a armazenagem do leite, determinaram que a relação entre a CBP e micro-organismos mesófilos apresenta um coeficiente de $r=0.65(\mathrm{P}<0,001)$.

A existência de uma infraestrutura mais adequada para ordenha, representada pela disponibilidade de ordenha canalizada, apresentou relação com baixa CBP e CBT inicial do leite cru. A ordenha canalizada, quando higienizada de forma adequada, minimiza o contato do leite com microorganismos provenientes do ambiente e otimiza o tempo para resfriamento da matéria-prima na propriedade leiteira (CITADIN et al., 2009).

A adoção de boas práticas, tais como o pre-dipping, também apresentou relação com baixa CBP, CBT e CCS inicial do tanque de expansão direta. Relações inversas também ocorreram para elevada CBT e CBP (Figura 2). A superfície dos tetos veicula micro-organismos contaminantes causadores de mastite e aumenta a contagem de micro-organismos mesófilos no leite. A utilização do pre-dipping reduz a quantidade desses microorganismos incorporados ao leite cru no momento da ordenha, dificultando também a ocorrência de microorganismos patogênicos no canal do teto, em especial aqueles de origem ambiental, que podem elevar a CCS, devido ao processo inflamatório. Ao avaliar a qualidade microbiológica de leite cru estocado em tanques de expansão, ELMOSLEMANY et al. (2010) evidenciaram que a quantidade de sujidade nos tetos antes da preparação para a ordenha foi positivamente relacionada à contagem de microorganismos psicrotróficos e aeróbios totais, assim como produtores que afirmaram fazer aplicação de 


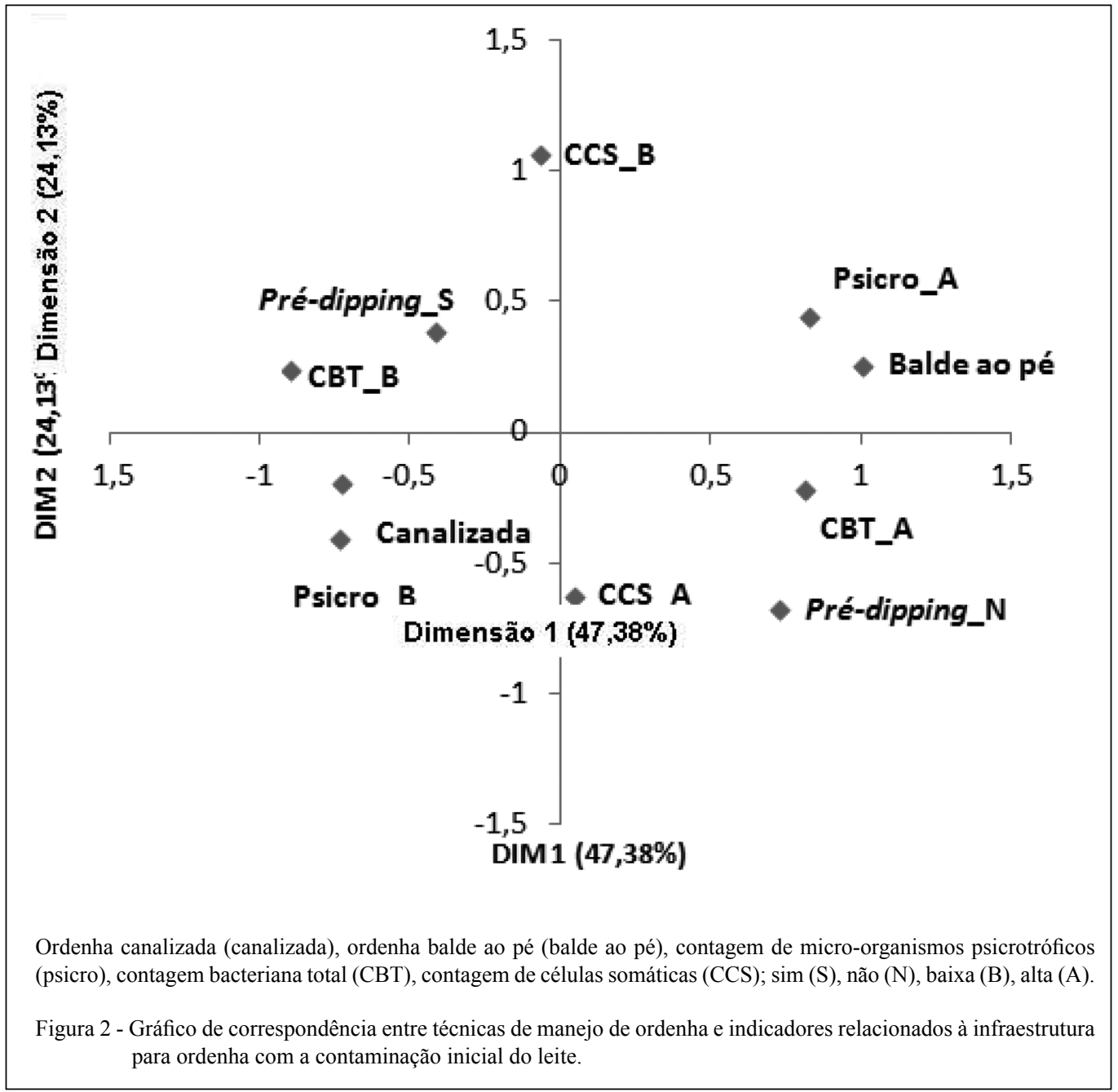

pre-dipping apresentaram menor CBT no leite cru resfriado. Em outro trabalho, a aplicação de boas práticas, incluindo descarte dos três primeiros jatos, lavagem dos utensílios de ordenha e pre-dipping, resultou em redução média de CBT e CCS de 86,99 e $51,85 \%$, respectivamente (VALLIN et al., 2009). De modo semelhante, outros trabalhos têm relacionado a adoção de práticas recomendadas de manejo de ordenha, como o pre-dipping, com a redução de CCS no leite cru refrigerado (GOODGER et al., 1993).

\section{CONCLUSÃO}

Tanques resfriadores por expansão direta, modelo de duas e quatro ordenhas, quando utilizados dentro de suas especificações quanto ao volume de leite a ser resfriado, permitem a manutenção da qualidade microbiológica do leite em termos de contagem bacteriana total (CBT) e contagem total de bactérias psicrotróficas (CBP), ao longo do tempo, em sistemas de transporte a granel do leite ao laticínio, com coleta a cada 48 horas.

A contagem total de bactérias psicrotróficas (CBP) foi maior em tanques de quatro ordenhas, em comparação aos tanques de duas ordenhas.

A contagem inicial de micro-organismos no leite cru apresenta elevada importância para a qualidade microbiológica final da matéria-prima.

\section{AGRADECIMENTOS}

À Fundação de Amparo à Pesquisa e Inovação do Estado de Santa Catarina (FAPESC), pelo recurso financeiro, ao Instituto Federal Catarinense (IFC) de Concórdia e aos produtores de leite, por disponibilizarem a estrutura laboratorial e as propriedades leiteiras, respectivamente.

\section{COMITÊ DE ÉTICA HUMANA}

Comitê de ética em seres humanos da plataforma Brasil - Ministério da Saúde, número de referência 04389812.7.0000.0118.

Ciência Rural, v.45, n.5, mai, 2015. 


\section{REFERÊNCIAS}

ARCURI, E.F. et al. Contagem, isolamento e caracterização de bactérias psicrotróficas contaminantes de leite cru refrigerado. Ciência Rural, v.38, n.8, p.2250-2255, 2008. Disponível em: $\quad<$ http://www.scielo.br/scielo.php?script=sci arttext\&pid=S0103-84782008000800025\&lng=en\&nrm=iso $>$. Acesso em: 09 set. 2014. doi: 10.1590/S0103-84782008000800025.

ARCURI, E.F. Efeito do crescimento de Pseudomonas sp. proteolítica na estabilidade do leite ao etanol. In: CONGRESSO NACIONAL DE LATICÍNIOS, 21., Juiz de Fora, MG. Revista do ILCT, v.59, n.339, p.140-144, 2004.

BRASIL. Ministério da Agricultura, Pecuária e Abastecimento. Instrução normativa n.62. Diário Oficial da República Federativa do Brasil, n.251, p.6-11, seção 1, 2011.

CATANIO, F.S. et al. Refrigerated raw milk quality of a processing plant in the north of Parana after the implementation of changes imposed by NI 62 of 2011. Semina: Ciências Agrárias, v.33, p.3171-3180, 2012.

CBQL. Tanques de refrigeração: recomendações do comitê de equipamentos/Conselho Brasileiro de Qualidade do Leite. São Paulo: Quiron. 2006. 28 p.

CEMPÍRKOVÁ, R.; MIKULOVÁ, M. Incidence of psychrotrophic lipolytic bacteria in cow's raw milk. Czech Journal of Animal Science, v.54, p.65-73, 2009.

CHAMPAGNE, C.P. et al. Psycrhrotrops in dairy products: their effects and their control. Critical Reviews in Food Science and Nutrition, v.34, p.1-30, 1994. Disponível em: <http://www. tandfonline.com/doi/abs/10.1080/ 10408399409527648>. Acesso em: 7 mar. 2014. doi: 10.1080/10408399409527648.

CITADIN, Â.S. et al. Qualidade microbiológica de leite cru refrigerado e fatores associados. Revista Brasileira Saúde Produção Animal, v.10, n.1, p.52-59, 2009.

ELMOSLEMANY, A.M. et al. The association between bulk tank milk analysis for raw milk quality and on-farm management practices. Preventive Veterinary Medicine, v.95, p.32-40, 2010.

FRÜHLING, S.W. Modelagem matemática do crescimento bacteriano no leite cru. 2013. 80f. Dissertação (Mestrado em Modelagem Matemática) - Departamento de Ciências Exatas e Engenharia UNIJUI, Ijui, RS.

GOODGER, W.J. et al. The association of milking management practices with bulk tank somatic cell counts. Preventive Veterinary
Medicine, v.15, p.235-251, 1993. Disponível em: <http://www. sciencedirect.com/science/article/pii/016758779390096C $>$. Acesso em: 7 fev. 2014. doi: 10.1016/0167-5877(93)90096-C.

GUERREIRO, P.K. et al. Qualidade microbiológica de leite em função de técnicas profiláticas no manejo de produção. Ciências Agrotécnicas, v.29, p.216-222, 2005. Disponível em: <http://www.scielo.br/scielo.php?script=sci_arttext\&pid $=\mathrm{S} 1413-70542005000100027>$. Acessado em: 7 fev. 2014. doi: 10.1590/S1413-70542005000100027.

LEITNER, G. et al. The influence of storage on the farm and in dairy silos on milk quality for cheese production. International Dairy Journal, v.18, p.109-113, 2008. Disponível em: <http:// www.sciencedirect.com/science/article/pii/S0958694607001793>. Acesso em: 20 nov. 2013. doi: 10.1016/j.idairyj.2007.09.001.

LORENZETTI, D.K. Influência do tempo e da temperatura no desenvolvimento de microrganismos psicrotróficos no leite cru de dois estados da região sul. 2006. 71f. Dissertação (Mestrado em Tecnologia de Alimentos) - Departamento de Tecnologia, Universidade Federal do Paraná, Curitiba, PR.

NIELSEN, S.S. Plasmin system and microbial proteases in milk: characteristics, roles, and relationship. Journal of Agricultural and Food Chemistry, v.50, p.6628-6634, 2002. Disponível em: $<$ http://pubs.acs.org/doi/abs/10.1021/jf0201881>. Acess em: 20 nov. 2014. doi: 10.1021/jf0201881.

SANTOS, P.A.D. Avaliação do leite cru refrigerado produzido na região sudoeste do estado de goiás estocado por diferentes períodos. 2008. 50f. Tese (Doutorado em Ciência Animal) - Pós graduação em Ciência Animal, UFG, Goiânia, 2008.

SAS. INSTITUTE INC. SAS/STAT User's guide. Versão 8.2. Cary NC, 2005. V.I, II e III.

SILVA, N.D. et al. Analises microbiológicas de alimentos e água. São Paulo: Varela, 2010. 624 p.

VALLIN, V.M. et al. Melhoria da qualidade do leite a partir da implantação de boas práticas de higiene na ordenha em 19 municípios da região central do Paraná. Semina: Ciências Agrárias, v.29, p.181-188, 2009. Disponível em: <http://www.uel. $\mathrm{br} / \mathrm{revistas} / \mathrm{uel} /$ index.php/semagrarias/article/view/2661>. Acesso em: 7 dez. 2013. doi: 10.5433/1679-0359.2009v30n1p181.

VINHOLIS, M.D.M.B.; BRANDÃO, H.D.M. Economia de escala no processo de resfriamento do leite. Ciência e Agrotecnologia, v.33, p.245-251, 2009. Disponível em: <http://www.scielo.br/ scielo.php?script=sci_arttext\&pid=S1413-70542009000100034>. Acesso em: 10 jan. 2014. doi: 10.1590/S1413-70542009000100034. 